\title{
Dynamic Hygrothermal Models for Monumental, Historic Buildings with HVAC Systems: Complexity shown through a case study.
}

\author{
Magda Posani ${ }^{1,}{ }^{*}$, Maria Do Rosario Veiga ${ }^{1}$, Vasco Peixoto de Freitas ${ }^{2}$, Karin Kompatscher ${ }^{3}$, and Henk Schellen $^{3}$ \\ ${ }^{1}$ LNEC - National Laboratory of Civil Engineering, Department of buildings, Lisbon, Portugal \\ ${ }^{2}$ CONSTRUCT(LFC), Faculty of Engineering of the University of Porto (FEUP), Department of civil engineering, Porto, Portugal \\ ${ }^{3} \mathrm{TU} / \mathrm{e}$ - Eindhoven University of Technology, Department of the built environment, Eindhoven, The Netherlands
}

\begin{abstract}
Our global climate is changing and the problem got so serious that the European Commission is calling for a climate-neutral Europe by 2050. To reach such an ambitious and urgent goal, an energy efficient renovation of the existing building stock is needed. Nonetheless, some buildings must be treated with special attention because of their historical value. Thus, it is advisable to evaluate their retrofit with the aid of calibrated hygrothermal simulation models, whose calibration can be complex and time demanding. This work shows the strategy adopted for obtaining a calibrated model for a XVI-century construction located northern Italy, by means of indoor air temperature and relative humidity monitoring, plus $\mathrm{CO}_{2}$ measurements and in situ inspection. This study accounts for the first 9 months of measurements performed on the case study and it adopts HAMBase as a simulation tool because of its ability to combine heat and moisture calculations in monumental buildings with HVAC systems.

This paper aims at showing the main problems found in developing and calibrating the simulation model while defining a procedure to overcome them. The major outcome of the study is that the stratification of temperature detected in the main monumental room could be successfully modelled via dividing this space into different zones, vertically, by introducing fictitious interzonal surfaces made of a material with high thermal conductivity and vapour permeability. All in all, the strategy adopted in this work can be used by other researchers and professionals to overcome problems that can be commonly met when modelling similar historic constructions.
\end{abstract}

\section{Introduction}

Our global climate is changing and the problem got so serious that the European Commission is calling for a climate-neutral Europe by 2050 [1]. To reach such an ambitious and urgent goal, the strategic importance of an energy efficient renovation of the existing building stock is evident [2]. Nonetheless, some buildings must be treated with special attention because of their historical value. For those buildings, literature provides an extended variety of possible retrofit solutions [3], but all interventions have to be studied in detail in the context of critical-preservation [4], avoiding risks for the original materials [5] as well as for the ancient artworks and artefacts that those buildings often contain [6].

Dynamic hygrothermal simulation tools are thus largely adopted [7-9] for forecasting risks and benefits involved by retrofitting scenarios, while accounting for the characteristics of the historic building and its specific boundary conditions. In order to reduce the uncertainties of the simulation outputs and obtain a reliable predictive tool, the model must be calibrated against data measured via in situ monitoring $[10,11]$. This process of calibration can be complex and time-demanding for historic buildings, because of the difficulty of collecting documents and information about the construction and its components, plus the impossibility of performing destructive tests. What is more, the complexity increases when considering monumental buildings with large dimensions and HVAC systems. This paper discusses the problems found while developing and calibrating a simulation model for the monumental library of San Giorgio in Poggiale, located in Bologna, northern Italy. All in all, the outcomes of the study can be useful for other researchers and professionals to overcome problems that can be commonly met when dealing with similar historic constructions, i.e. thermal stratification, lack of documental information and presence of several HVAC systems located at different heights.

The paper is structured as follows. First, section 2.1 provides the characteristics of the building and its systems. Section 2.2 describes the methods adopted for data acquisition and section 2.3 presents the hygrothermal simulation model developed for the case study.

In paragraph 3 the results obtained in terms of climate data (paragraph 3.1), measurements (paragraph 3.2, 3.3) and outcomes of the simulations (paragraph 3.4) are given and discussed. Conclusions are drawn in paragraph 4.

\footnotetext{
* Corresponding author: mposani@lnec.pt
} 


\section{Methodology}

First, the main characteristics of the building were defined through documental research, visual inspection and by taking advantage of the expertise and knowledge of the technicians that worked on the refurbishment and maintenance of the building. Outdoor climate data acquisition and $\mathrm{CO}_{2}$ measurements were performed for the sake of obtaining more information on the case study. A continuous monitoring of indoor air temperature and relative humidity was performed as well. The information obtained (structure geometry, materials, HVAC systems, occupancy, outdoor climate) was used to develop a numerical simulation model that was then calibrated via comparing its outputs against the measured indoor climate data. The indoor monitoring and the simulation outputs refer to the period 20th December 2018 - 20th September 2019, which is going to be referred to as the "measurement period" in the rest of the paper.

\subsection{Case study characterization}

\subsubsection{Building}

This work is focused on the Library of San Giorgio in Poggiale, located in the city of Bologna, Italy. This building was originally constructed in the XVI century as a Baroque-style church, it was severely damaged in 1943 and it was then subjected to two major rehabilitation and refurbishment interventions.

The monumental building has a height of about $20 \mathrm{~m}$ and its volume is divided in three parts: an underground space that was constructed in the 1970s, currently adopted as a depot, a main space that hosts the library and an unheated attic, as shown in Figure 1.

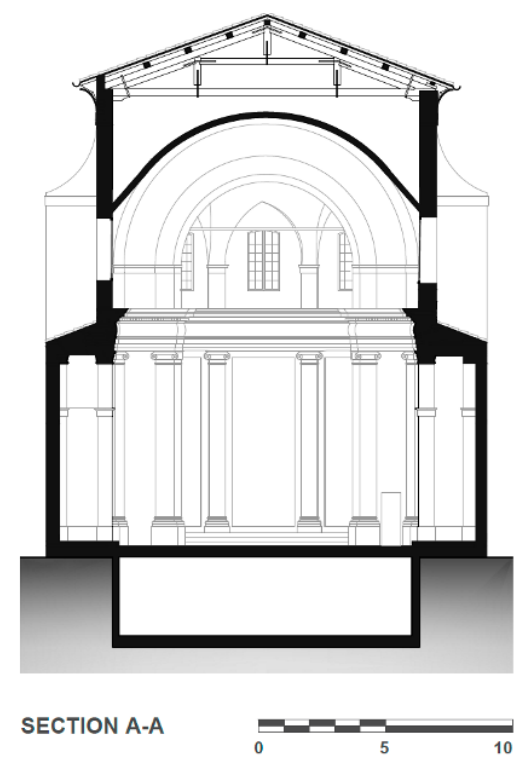

Fig. 1. Vertical section of the building. From bottom to top: the space is divided into an underground depot, a main room and an attic.

The building is partly connected to different adjacent buildings, as shown in Figure 2.
The envelope is characterized by massive masonry walls, single glazing windows and a wooden roof structure covered by wooden battens and ceramic tiles. The ceiling was constructed during the rehabilitation works performed in the 70s and it was designed following the traditional technique of the "reed-false-vault" [12], which consists of using a wooden vaulted frame structure, covered at the inner side with a mat of reed and finished with a layer of gypsum plaster. The floor structure and the underground depot construction date back to the 70 s.

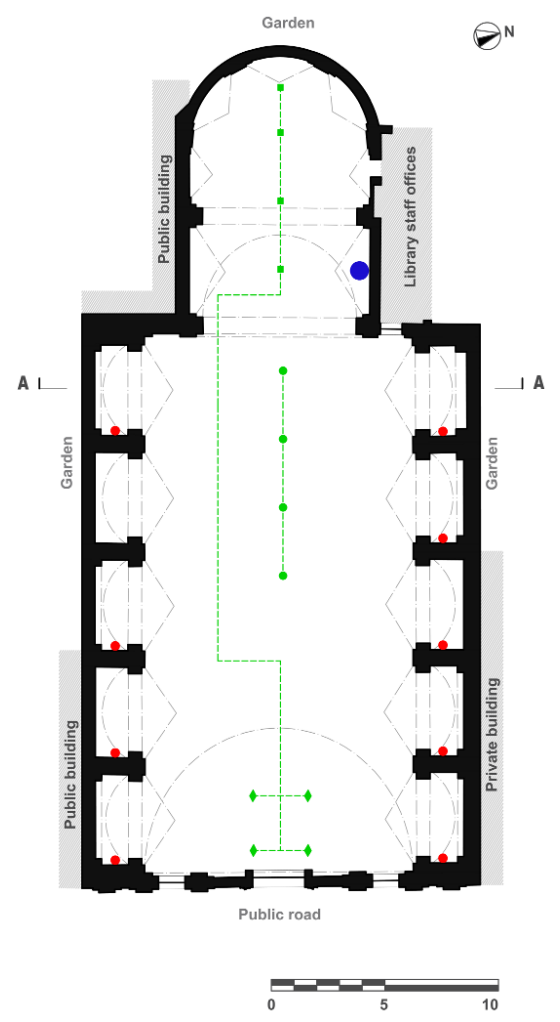

Fig. 2. Plan of the building. The original structure of the church, made of a simple nave hall and 10 self-contained lateral chapels, is readable. The terminal units of the first heating and cooling system are shown in red while the blue dot indicates the location of the second system, responsible for heating, cooling and humidification. The green elements refer to the recirculation and exhaust air ventilation system: squares and rhombuses respectively indicate outlets and inlets of the recirculation part, circles represent the outlets of the exhaust air ventilation system.

\subsubsection{Building systems}

The location of building systems is shown in Figure 2. A first heating and cooling system is composed of 9 air handling units (AHUs), positioned in the lateral chapels of the building, whose air inlets are located at about $4 \mathrm{~m}$ height. The second system consists of an AHU located in the apse, at about $7 \mathrm{~m}$ height, which is further equipped with a humidifier.

The last technical system is responsible for recirculation and exhaust air expulsion. Windows are always kept closed and, thus, the fresh air supply relies on infiltration.

The main technical details of the systems are summarized in Table 1. 
Table 1. HVAC systems in San Giorgio in Poggiale Library.

\begin{tabular}{|c|c|c|c|}
\hline & $\begin{array}{c}\text { Inlets } \\
\text { height }\end{array}$ & Type & Capacity \\
\hline \multirow{2}{*}{$\begin{array}{c}\text { system 1: } \\
9 \text { AHUs } \\
\text { in the } \\
\text { chapels }\end{array}$} & \multirow{2}{*}{$\approx 4 \mathrm{~m}$} & Heating & $\begin{array}{c}6.52 \mathrm{~kW} \\
\text { (each AHU) }\end{array}$ \\
\hline & & Cooling & $\begin{array}{c}6.57 \mathrm{~kW} \\
\text { (each AHU) }\end{array}$ \\
\hline \multirow{3}{*}{$\begin{array}{c}\text { system 2: } \\
1 \mathrm{AHU} \\
\text { in the apse }\end{array}$} & \multirow{3}{*}{$\approx 7 \mathrm{~m}$} & Heating & $115.00 \mathrm{~kW}$ \\
\hline & & Cooling & $93.70 \mathrm{~kW}$ \\
\hline & & Humidification & $45.00 \mathrm{~kg} / \mathrm{h}$ \\
\hline \multicolumn{4}{|c|}{$\begin{array}{l}\text { Systems } 1 \text { and } 2 \text { have } 3 \text {-speed fans and they are regulated } \\
\text { to work at low speed during closing hours, in winter. } \\
\text { Setpoints are dynamic and they are occasionally changed } \\
\text { and set on a static value manually, according to the needs } \\
\text { defined by the library staff. }\end{array}$} \\
\hline \multirow{2}{*}{$\begin{array}{l}\text { system 3: } \\
\text { at the } \\
\text { ceiling level }\end{array}$} & \multirow{2}{*}{$\approx 17 \mathrm{~m}$} & Recirculation & $3000 \mathrm{~m}^{3} / \mathrm{h}$ \\
\hline & & $\begin{array}{c}\text { Exhaust air } \\
\text { expulsion }\end{array}$ & $3200 \mathrm{~m}^{3} / \mathrm{h}$ \\
\hline
\end{tabular}

\subsection{Data acquisition}

\subsubsection{Outdoor climate data}

For the sake of performing hygrothermal simulations, outdoor climate data are fundamental. Therefore, the measurements of the hourly weather data were provided by the public entity ARPAE (temperature, relative humidity, global solar radiation, wind speed and direction) for the 9-month-period considered in this study. The missing data (cloud cover, diffuse solar radiation) was taken from the Test Reference Year (TRY) provided by the Software Meteonorm [13].

\subsubsection{CO2 concentration}

Carbon dioxide $\left(\mathrm{CO}_{2}\right)$ measurement can be used to estimate indoor occupancy [14].

Therefore, $\mathrm{CO}_{2}$ concentration was continuously measured in the period 20th December - 30th December 2018, through a TELAIRE T7001 sensor (accuracy of \pm $50 \mathrm{ppm}$ ), with a logging interval of 10 minutes. The sensor was located in one of the chapels, at about $2.5 \mathrm{~m}$ height and far from windows and outdoor facing doors, to avoid people and drafts interference. The 10-days-period of monitoring provided the opportunity to observe the gas concentration during average days of normal library use, holidays closure days and special openings for exhibitions and organized events, when more users are expected to visit the building.

\subsubsection{Microclimate monitoring $(T, R H)$}

Indoor air Temperature ( $\mathrm{T}$ ) and Relative Humidity (RH) were measured from $20^{\text {th }}$ December 2018 to $20^{\text {th }}$ September 2019. The instruments adopted for the measurements and data logging were four HOBO UX100003 (accuracy: $\pm 0.21^{\circ} \mathrm{C}, \pm 3.5 \%$ for $25-85 \% \mathrm{RH}$ and $5 \%$ out of this range) and one HOBO U12-013 (accuracy: $\pm 0.35^{\circ} \mathrm{C}, \pm 2.5 \%$ for $10-90 \% \mathrm{RH}$ and $5 \%$ out of this range).

Three dataloggers (labelled as N1, N2, S2 in Figure 3) were located on the top of bookshelves in the ex-church chapels, at about $2.50 \mathrm{~m}$ height, in order to avoid direct users' interaction with the sensors.

One data logger (named $\mathrm{W}$ in Figure 3) was positioned in the apse, at about $0.5 \mathrm{~m}$ height. The last sensor (S1 in Figure 3) was located under the direct influence of the first heating/cooling system (system 1 in Table 1) to enhance the completeness of the information given by the library staff concerning the working hours of the heating system. The underground space was not accessible because of the precious artefacts that are stored in there. The data regarding air temperature and relative humidity in this space were provided by the library staff who always keeps the depot monitored. It was not possible to access the attic too, thus no measurements were performed in this space as well.

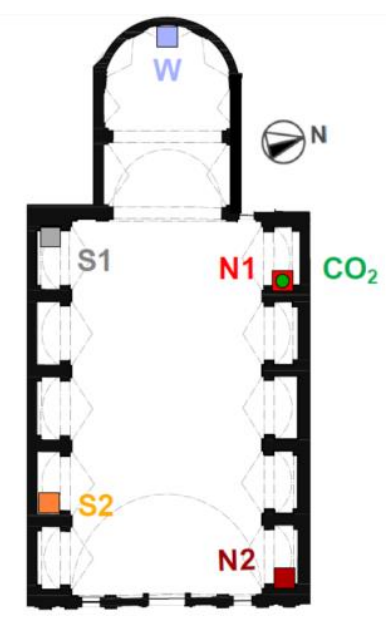

Fig. 3. Location of the sensors used for measuring temperaturerelative humidity (squares labelled as $\mathrm{S} 2, \mathrm{~S} 1, \mathrm{~W}, \mathrm{~N} 1, \mathrm{~N} 2$ ) and $\mathrm{CO}_{2}$ concentration (green dot).

\section{3 hygrothermal simulation model}

A numerical model was defined through HAMBase [15] simulation tool. HAMbase is able to calculate heat and moisture flows in a multi-zone building model by accounting for the outdoor climate, building envelope characteristics, HVAC systems and internal gains. Among its calculation outputs, there are the indoor climate and energy use for each zone of the model.

This simulation tool is chosen for this research as it appears suitable for the aims of the study and because it had already been successfully adopted for analyses performed on monumental and historic buildings by several researchers [16-19].

\subsubsection{Input data}

The main construction assemblies adopted as input data for the simulations are summarized in Table 2. 
Table 2. Material characteristics defined for the main components of the building. This information is used as model input.

\begin{tabular}{|c|c|c|c|}
\hline & $\begin{array}{c}\text { Construction } \\
\text { type }\end{array}$ & $\begin{array}{c}\text { Material } \\
\text { (from indoor } \\
\text { to outdoor } \\
\text { side) } \\
\end{array}$ & $\begin{array}{c}\text { Thickness } \\
\text { [cm] }\end{array}$ \\
\hline Facade & $\begin{array}{l}\text { massive } \\
\text { masonry }\end{array}$ & $\begin{array}{l}\text { gypsum plaster } \\
\text { full bricks }\end{array}$ & $\begin{array}{c}3 \\
90 \\
\end{array}$ \\
\hline $\begin{array}{l}\text { External } \\
\text { walls }\end{array}$ & $\begin{array}{l}\text { massive } \\
\text { masonry }\end{array}$ & $\begin{array}{l}\text { gypsum plaster } \\
\text { full bricks } \\
\text { mineral render }\end{array}$ & $\begin{array}{c}3 \\
60 \\
3 \\
\end{array}$ \\
\hline $\begin{array}{l}\text { Internal } \\
\text { walls }\end{array}$ & $\begin{array}{l}\text { massive } \\
\text { masonry }\end{array}$ & $\begin{array}{l}\text { gypsum plaster } \\
\text { full bricks } \\
\text { gypsum plaster }\end{array}$ & $\begin{array}{c}3 \\
75 \\
3 \\
\end{array}$ \\
\hline Roof & $\begin{array}{l}\text { Wooden } \\
\text { structure }\end{array}$ & $\begin{array}{c}\text { wood } \\
\text { ceramic tiles } \\
\end{array}$ & $\begin{array}{c}10 \\
3 \\
\end{array}$ \\
\hline $\begin{array}{l}\text { Vaulted } \\
\text { ceiling }\end{array}$ & $\begin{array}{l}\text { Reed-False } \\
\text { vaults }\end{array}$ & $\begin{array}{c}\text { gypsum plaster } \\
\text { Reed } \\
\end{array}$ & $\begin{array}{l}3 \\
5 \\
\end{array}$ \\
\hline $\begin{array}{l}\text { Floor - } \\
\text { facing } \\
\text { the } \\
\text { deposit }\end{array}$ & $\begin{array}{l}70 s \text { - Hollow } \\
\text { brick and } \\
\text { Concrete } \\
\text { structure }\end{array}$ & $\begin{array}{c}\text { hardwood } \\
\text { (pavement) } \\
\text { light concrete } \\
\text { Hollow bricks } \\
\text { gypsum plaster }\end{array}$ & $\begin{array}{c}2.5 \\
8 \\
25 \\
3 \\
\end{array}$ \\
\hline $\begin{array}{l}\text { Floor - } \\
\text { against } \\
\text { ground }\end{array}$ & $\begin{array}{c}70 s- \\
\text { Concrete } \\
\text { structure }\end{array}$ & $\begin{array}{c}\text { hardwood } \\
\text { (pavement) } \\
\text { light concrete } \\
\text { sand blinding } \\
\end{array}$ & $\begin{array}{l}2.5 \\
10 \\
40 \\
\end{array}$ \\
\hline Windows & $\begin{array}{l}\text { single glazing } \\
\text { with indoor } \\
\text { curtains }\end{array}$ & \multicolumn{2}{|c|}{$\begin{array}{l}\mathrm{U} \text {-value }=3.2 \mathrm{~W} /\left(\mathrm{m}^{2} \mathrm{~K}\right) \\
\text { Solar gain factor }=0.6\end{array}$} \\
\hline
\end{tabular}

The inputs concerning HVAC systems and outdoor weather were defined according to the case study characterization presented in section 2 and the simulation period equals the measurement period. One extra year was calculated in advance in order to start the simulation period with more realistic indoor air temperature and relative humidity data. For this extra year, the outdoor climate boundary condition adopted was the Test Reference Year.

As long as the interaction with the ground is concerned, it

was simplified considering a constant temperature soil.

It is indeed known that ground temperature is subjected to smaller variations than the outdoor air one and that it remains relatively constant throughout the year, below a certain depth [20]. The temperature was assumed as equivalent to the annual average temperature of the ground surface [21], which was approximated with the annual average outdoor air temperature, that is $14.26^{\circ} \mathrm{C}$ for Bologna, according to the data of the TRY.

Daytime Infiltration was neglected while the effect of mechanical recirculation and exhaust air ventilation during night was accounted. Walls facing towards other heated spaces, i.e. the adjacent buildings, were modelled as adiabatic components. The underground space was not modelled as it is not part of the historic structure. Nonetheless, the influence of the depot indoor air temperature on the rest of the building was taken into account. Internal gains were disregarded because of the low occupancy (derived from $\mathrm{CO}_{2}$ measurement results, see 3.2) and the short time of opening hours (short use of the few small appliances in a massive air volume). Thermal bridges were not introduced in the model.

\subsubsection{Zones}

Given that each zone is assumed to have uniform air temperature and relative humidity, it wasn't possible to model the main library room as a singular zone because of the temperature stratification detected during the heating season (see 3.1). What is more, due to the lack of information on the energy use in time, modelling the main library volume as one zone subjected to the heating capacity of all the building systems was leading to have the air temperature matching the setpoint of the systems constantly, which was not representative of the real indoor microclimate behaviour. This problem was overcome by dividing the main volume into three zones, as shown in Figure 4. This division was created, in the numerical model, by introducing fictitious interzonal surfaces made of $0.5 \mathrm{~cm}$ of a material defined by the user to have high thermal conductivity and water vapour permeability $\left(\lambda=50 \mathrm{Wm}^{-1} \mathrm{~K}^{-1}, \mu=1\right)$.

The first zone spans from the floor to $2 \mathrm{~m}$ height, with no HVAC systems present. The second zone goes up to $7 \mathrm{~m}$ and it is directly conditioned by the first heating and cooling system (system 1 in Table 1). The third zone is characterized by the presence of the air handling unit responsible for heating, cooling and humidification (system 2 in Table 1). The unheated attic was also modelled as a separate zone.

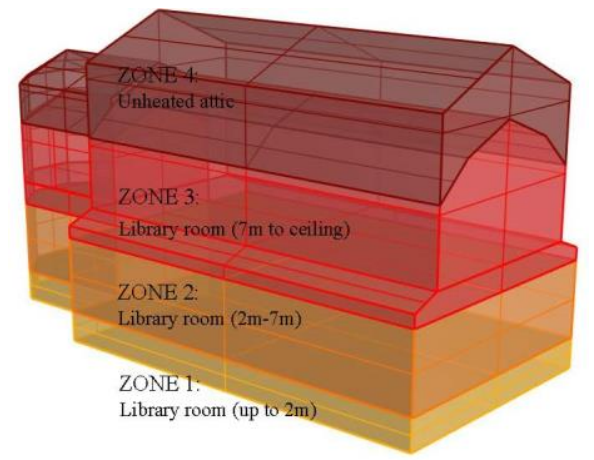

Fig. 4. Representation of the zones defined for the model. The main room of the library is divided into three zones, vertically, and the unheated attic is also modelled as a separate zone.

\section{Results and discussion}

\subsection{Outdoor climate data}

In Figure 5, air temperature, relative humidity and specific humidity obtained via ARPAE data are shown together with the ones of the test reference year, in order to provide a comparison between the specific weather behaviour during the measurement period and the average climate.

According to TRY, the typical climate in Bologna has temperatures ranging from $<-5^{\circ} \mathrm{C}$, in winter, to $>35^{\circ} \mathrm{C}$ in summer, averaging $14^{\circ} \mathrm{C}$, while outdoor relative 
humidity spans $21-100 \%$, with a mean yearly value of $70 \%$.

The analysed period has a behaviour that is noticeably different from the TRY, for example in May differences of more than $20^{\circ} \mathrm{C}$ can be found. Thus, the use of real data was preferred to the TRY one, for the boundary conditions of the simulation period (see 2.3.1), for the sake of having more realistic results.

\section{$3.2 \mathrm{CO}_{2}$ concentration}

The measured indoor $\mathrm{CO}_{2}$ concentration spans from about $400 \mathrm{ppm}$ to less than $700 \mathrm{ppm}$. Considering that the outdoor concentration generally ranges between 375 and $450 \mathrm{ppm}$ [22], the indoor value overcomes the environmental one of less than $350 \mathrm{ppm}$, meaning that the indoor $\mathrm{CO}_{2}$ produced by occupancy is very low for the air volume contained in the monumental building and it indeed corresponds to a high indoor air quality in EN13779 standard [23]. This result of "low occupancy" is also coherent with the information given by the library staff. Based on this outcome, no heat gains due to occupancy were introduced in the simulation model.

\subsection{Microclimate monitoring $(\mathrm{T}, \mathrm{RH})$}

The data recorded for air temperature and relative humidity are shown in Figure 6, together with the specific humidity that is indirectly measured from those quantities. For most wintertime, sensors S1 (grey) registered higher temperatures than all the other sensors because of the direct influence of the heating system. In two periods, one in December and one at the end of April - beginning of May, the temperature difference between the grey data and the others was substantially reduced. It thus indicates the shut-down of the heating system located in the chapels (i.e. system 1 in Table 1), while system 2 was still heating, according to the schedule provided by the library staff. The measurements of Sensor S1 stopped in June, when it was removed because there was no more lack of information on the working schedule of the system

According to the temperature measurements shown in Figure 6, a temperature stratification is readable between $2.5 \mathrm{~m}$ and $0.5 \mathrm{~m}$ levels during winter, indeed all sensors located at $2.5 \mathrm{~m}$ level measured higher temperatures (red, dark red and orange data in the graphics) than the one recorded by the sensor positioned at $0.5 \mathrm{~m}$ level (light blue data in the graphic), for most time during winter. A similar behaviour can be found in the middle of august when the cooling systems are turned off.

\section{Outdoor climate in Bologna \\ (temperature, relative humidity, specific humidity)}
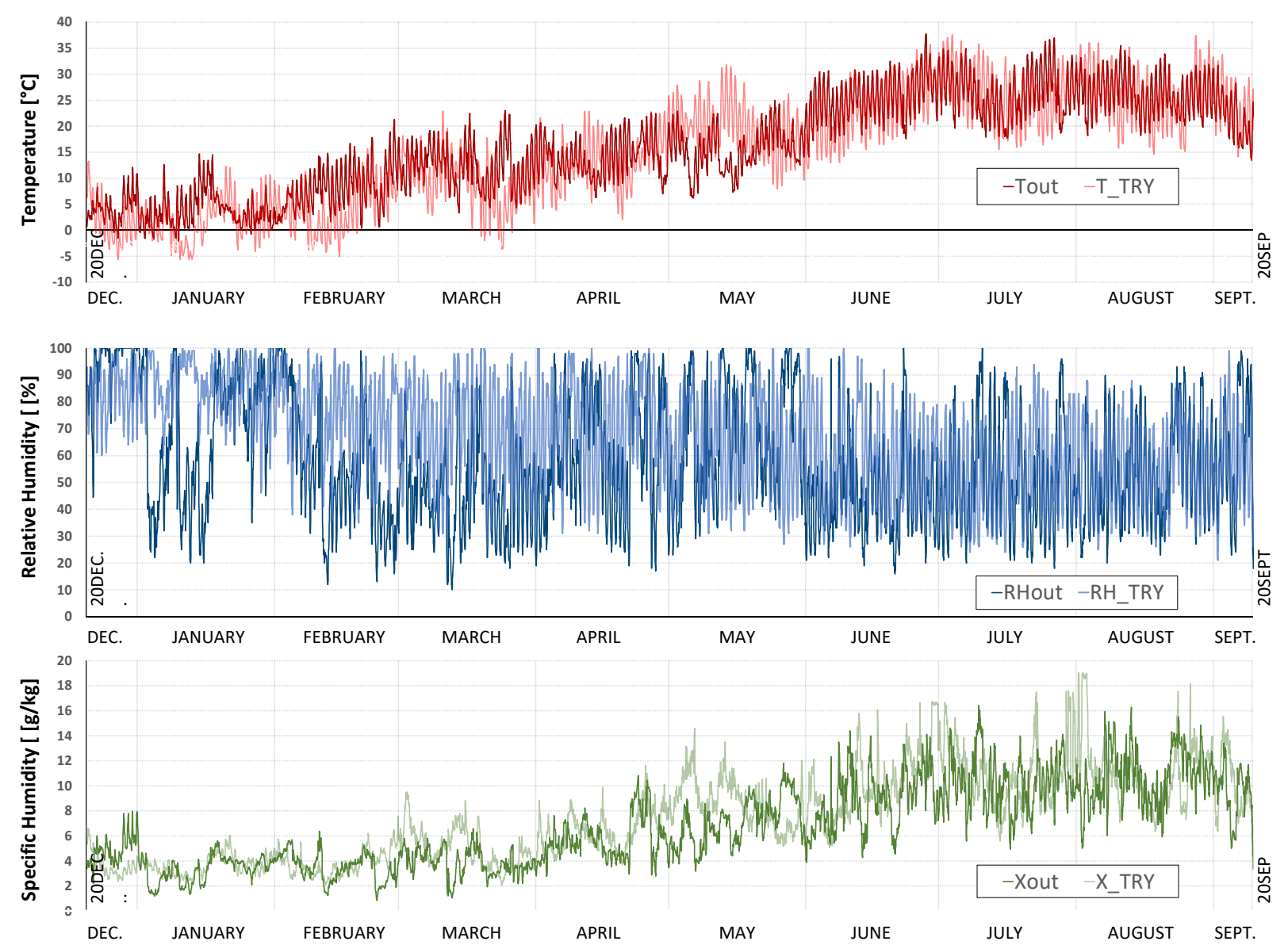

Fig. 5. Temperature, relative humidity and specific humidity data recorded by ARPAE for the city of Bologna in the period $20^{\text {th }}$ December $2018-20^{\text {th }}$ September 2019, in comparison with the data provided for the same period in the TRY (Test Reference Year) defined by Meteonorm software. 


\subsection{Hygrothermal simulations}

The comparison between measured and simulated indoor air temperature was used to calibrate the model.

During the calibration, the thickness of walls, roof, ceiling and floor assemblies was found to have little effect on temperature results, as well as ground temperature. Thus, those factors were kept unvaried. Windows thermal transmittance and solar gain factor had a noticeable influence on results. Their values were consequently chosen to improve the fit while being coherent with the type of windows considered. The introduction of internal walls, recirculation and ventilation in the model was found to improve the fit. Results were strongly improved by dividing the main room of the model in different zones and by accounting for the variations periodically introduced on setpoints and time schedules of the heating systems by the maintenance staff.

After the calibration, the simulation output, in terms of indoor air temperature, relative and specific humidity, were compared with the measured data.

The results obtained for the lowest zone are compared to the measurements recorded at $0.5 \mathrm{~m}$ level (sensor W). The outcomes obtained for zone 2 are compared to the average measurements performed at $2.5 \mathrm{~m}$ level (mean value of data recorded by sensors N1, N2, S2).

The comparison is shown in Figure 7, where also the simulated climate of zones 3 and 4 are displayed. Even though no experimental measurements were performed within these last two spaces, it appears useful to keep those results tracked to check their plausibility.

The statistical quantification of the error is shown in Table 1 and it accounts for three indexes that are suggested by ASHRAE Guideline, the International Performance Measurement and Verification Protocol (IPMVP) and the Federal Energy Management Program (FEMP) [24]. Those indexes are:

-NMBE, that quantifies the global difference between the real values and the predicted ones (recommended to be within $-5 \%,+5 \%$ );

-CV(RMSE), which gives an indication of the model ability to predict the overall load shape that is reflected in the data [24] (suggested $<20 \%$ );

$-\mathrm{R}^{2}$, which indicates how close simulated values are to the regression line of the measured values [24] (recommended $>0.75$ for calibrated models).

Table 1. Statistical quantification of the error

\begin{tabular}{r|c|c|c|c|c|c|}
\cline { 2 - 7 } & T1 & T2 & RH1 & RH2 & X1 & X2 \\
\cline { 2 - 7 } NMBE & $1 \%$ & $2 \%$ & $3 \%$ & $-4 \%$ & $5 \%$ & $1 \%$ \\
\cline { 2 - 7 } CV & $4 \%$ & $6 \%$ & $12 \%$ & $15 \%$ & $14 \%$ & $16 \%$ \\
$\mathrm{R}^{\wedge} 2$ & 0.95 & 0.90 & 0.89 & 0.86 & 0.96 & 0.95 \\
\cline { 2 - 7 } & & &
\end{tabular}

All the quantities simulated for the indoor climate (temperature, relative and specific humidity) comply with the acceptance range and the model is indeed considered calibrated for the first 9 months of measurements.

\section{Conclusion}

This study showed the construction of a calibrated hygrothermal model for a case study that has large dimensions, different HVAC systems located at different heights and a historical envelope that was restored and refurbished through the decades. The strategy provided is based on monitoring of air temperature and relative humidity, plus $\mathrm{CO}_{2}$ measurements and in situ inspection, and it is easily replicable.

The best choices done for improving the fit of the model with indoor climate measurements were:

- Dividing the main, monumental room into different zones, vertically, to consider the temperature stratification and the presence of different systems at different heights;

- Characterizing the building envelope by accounting for the information given by the technicians that participated in previous refurbishment works on the building, in order to overcome the lack of documental resources;

- Defining the influence of the HVAC systems on the indoor climate by considering detailed information given by the maintenance staff concerning the working time, dynamic setpoints, fans velocity schedules and how those settings were manually changed during the year;

- Locating a temperature sensor under the direct influence of one of the heating systems to provide reliable proofs of the working time of the building services, thus obtaining more complete information on the systems management.

The procedure proposed is similar to others adopted in studies on hygrothermal modelling of existing buildings, but specific suggestions are provided to overcome problems that can be commonly met in historic constructions (i.e. thermal stratification, presence of different systems at different heights in monumental spaces, lack of documental information). The main outcome of the study is that the stratification of temperature detected in the main room could be successfully modelled via dividing the space into different zones, vertically, by introducing fictitious interzonal surfaces made of a material with high thermal conductivity and vapour permeability.

All in all, the results presented are believed to be useful for helping other researchers and professionals to develop calibrated hygrothermal models for historic, massive buildings presenting similar complexity to the case study hereby discussed. This work is based on a limited period of measured data. Thus, the calibration will be checked with a complete year of measurements in future work. Furthermore, only one sensor was located at $0.5 \mathrm{~m}$ height and its measurements were considered as representative of the air temperature and relative humidity at $0.5 \mathrm{~m}$ level. Further sensors were recently installed in the building and the new measurements will be adopted to verify the accuracy of this assumption. 


\section{San Giorgio in Poggiale Library - Results of the firtst 9 months of indoor monitoring champaign}
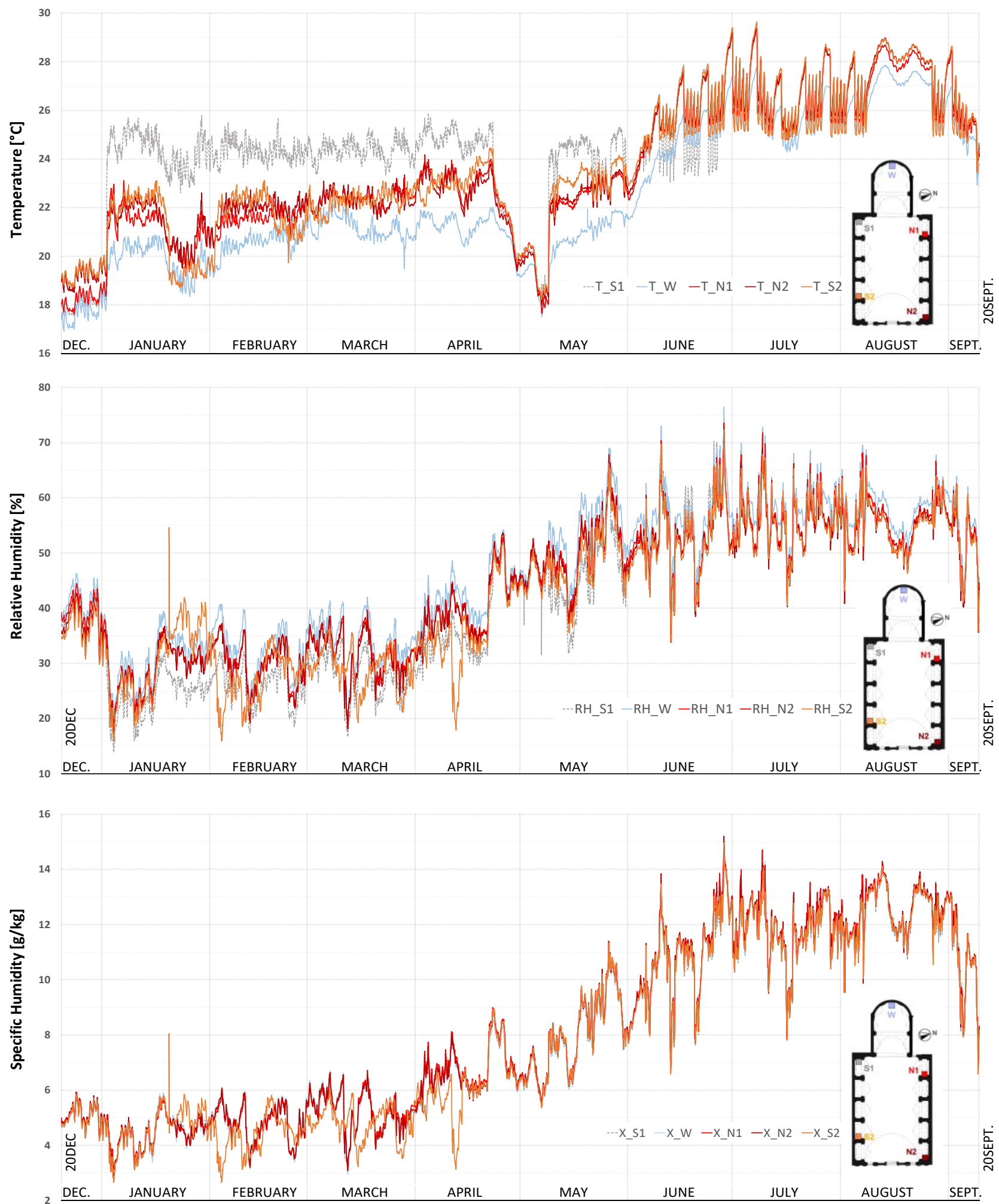

Fig. 6. Temperature and relative humidity directly measured in the case study and Specific humidity indirectly derived from them. The temperature graphic shows that grey data are frequently higher than all the others. That occurs because sensor S1 (grey) is located close to an air handling unit in order to provide information concerning the working schedule of the heating system. Red, dark red and orange lines represent the data collected by the sensors located at $2.5 \mathrm{~m}$ height whereas light blue data correspond to the measures performed at $0.5 \mathrm{~m}$ level by sensor $\mathrm{W}$. It is noticeable that in two periods, one in December and one at the end of April - beginning of May, the heating system located in the chapels is turned off, indeed the temperature difference between the grey data and the others is substantially reduced. Sensor S1 was removed in June as the working time of the cooling system was known, thus there was no need of using a sensor close to the air handling unit any longer. 

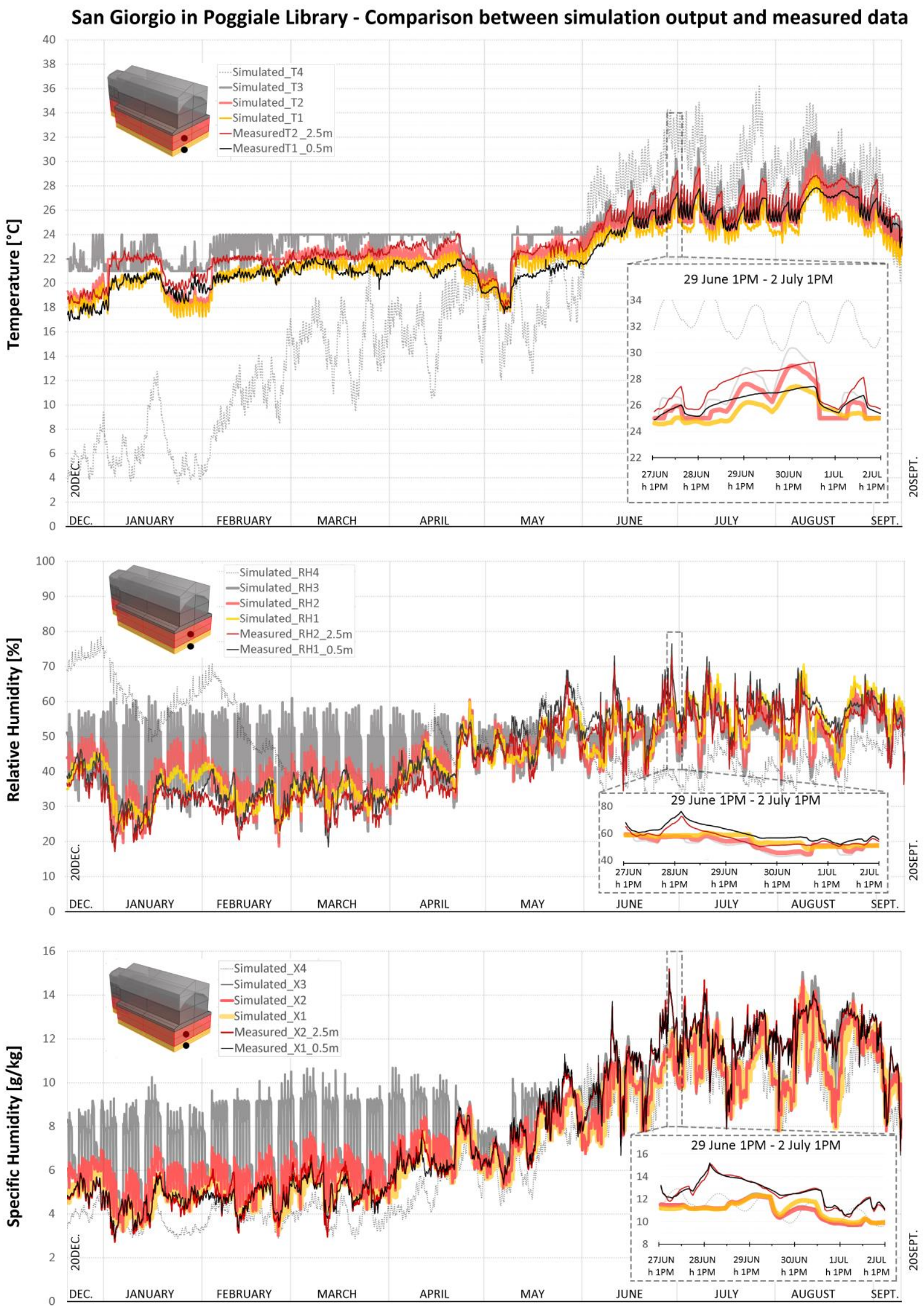

Fig. 7. Results of the calibrated hygrothermal model for the indoor climate (T, RH, X) of the case study. Grey lines represent the simulated data for zones 3 and 4. Thick red and yellow lines represent the simulated values for zone 2 and zone 1, which can be compared with the thin lines in dark red and black that represent the data measured data at $2.5 \mathrm{~m}$ and $0.5 \mathrm{~m}$ levels, respectively. 
The authors would like to thank Fondazione Carisbo and Genus Bononiae corporation, in particular its President Prof. Fabio Roversi-Monaco, Dr. Pierangelo Bellettini and Dr. Daniela Schiavina, for providing the authorization to perform the study. We also express our appreciation for the assistance provided by the library staff, especially Arc. Francisco Giordano and the technicians Giovanni Palladini, Claudio Fiorini. We thank ARPAE for providing meteorological data. The authors acknowledge the support given by TU/e (unit of Building Physics \& Services) in providing further experimental set-up to adopt in the future steps of the research. The authors thank the financial support provided by FCT and CONSTRUCT (UIDB/04708/2020) and the institutions hosting the research: FEUP and LNEC (Project PRESERVE - Preservation of renders of built cultural heritage).

\section{References}

1. European Commission, "2050 long-term strategy." [Online](2018)Available:https://ec.europa.eu/clima/p olicies/strategies/2050_en. [Accessed: 17-Jan-2020].

2. European Commission, "Going climate-neutral by 2050: A strategic long-term vision for a prosperous, modern, competitive and climate-neutral EU economy".[Online](2019)Available:https://op.europa. eu/en/publication-detail/-/publication/92f6d5bc-76bc11e9-9f05-01aa75ed71a1. [Accessed: 17-Jan-2020].

3. M. Posani, M. D. R. Veiga, and V. P. de Freitas, "Towards Resilience and Sustainability for Historic Buildings: A Review of Envelope Retrofit Possibilities and a Discussion on Hygric Compatibility of Thermal Insulations.”, Int. J. Archit. Herit. (2019)

4. G. Carbonara, "Energy efficiency as a protection tool.", Energy Build. 95,9-12 (2015)

5. E. Vereecken, L. Van Gelder, H. Janssen, and S. Roels, "Interior insulation for wall retrofitting - A probabilistic analysis of energy savings and hygrothermal risks.", Energy Build. 89, 231-244 (2015)

6. R. P. Kramer, M. P. E. Maas, M. H. J. Martens, A. W. M. van Schijndel, and H. L. Schellen, "Energy conservation in museums using different setpoint strategies: A case study for a state-of-the-art museum using building simulations.", Appl. Energy. 158, 446458 (2015)

7. S. A. Magalhães and V. P. De Freitas, "A complementary approach for energy efficiency and comfort evaluation of renovated dwellings in Southern Europe.", Energy Procedia. 132, 909-914 (2017)

8. C. Ferreira, V. P. de Freitas, and J. M. P. Q. Delgado, "The Influence of Hygroscopic Materials on the Fluctuation of Relative Humidity in Museums Located in Historical Buildings.", Stud. Conserv. (2019)

9. G. Semprini, C. Galli, and S. Farina, "Reuse of an ancient church: Thermal aspect for integrated solutions.", Energy Procedia. 133, 327-335 (2017)

10. G. B. A. Coelho, H. E. Silva, and F. M. A. Henriques, "Calibrated hygrothermal simulation models for historical buildings.", Build. Environ. 142, 439-450 (2018)

11. F. Roberti, U. F. Oberegger, and A. Gasparella, "Calibrating historic building energy models to hourly indoor air and surface temperatures: Methodology and case study.", Energy Build. 108, 236-243 (2015)

12. F. Bergonzoni and P. M. Branchesi, "La Chiesa di San Giorgio in Poggiale.", Cassa di Risparmio in Bologna. (1979)

13. METEOTEST Meteonorm - VErsion 6.0. Meteotest, Bern, Switzerland.

14. C. Jiang, M. K. Masood, Y. C. Soh, and H. Li, "Indoor occupancy estimation from carbon dioxide concentration.", Energy Build. 131, 132-141 (2016).

15. M. de Wit, "HAMBase: Heat, Air and Moisture Model for Building and Systems Evaluation, Bouwstenen.", Bouwstenen. (2006)

16. K. Kompatscher, S. Seuren, R. Kramer, J. Van Schijndel, and H. Schellen, "Energy efficient HVAC control in historical buildings: A case study for the Amsterdam Museum.”, Energy Procedia. 132, 892896 (2017)

17. H. L. Schellen and A. W. M. van Schijndel, "Setpoint control for air heating in a church to minimize moisture related mechanical stress in wooden interior parts." Build. Simul. 4,79-86 (2011)

18. Van Aarle, M. A. P., A. W. M. van Schijndel, and H. L. Schellen. "A hypocaust hot air floor heating system in the netherlands." In 12th Symposium for Building Physics, March 29-31, 2007, Dresden, Germany. Technische Universität Dresden. pp. 206213.

19. Z. Huijbregts, R. P. Kramer, M. H. J. Martens, A. W. M. van Schijndel, and H. L. Schellen, "A proposed method to assess the damage risk of future climate change to museum objects in historic buildings." Build. Environ. 55, 43-56 (2012)

20. P. M. Congedo, C. Lorusso, M. G. de Giorgi, and D. Laforgia, "Computational fluid dynamic modeling of horizontal air-ground heat exchangers (HAGHE) for HVAC systems.” Energies. 7, 8465-8482 (2014)

21. M. Derradji and M. Aiche, "Modeling the soil surface temperature for natural cooling of buildings in hot climates", Procedia Computer Science. 32, 615-621 (2014)

22. M. Schell and D. Inthout, "Ventilation Using CO 2." ASHRAE J. 43(2), 18-29 (2001)

23. CEN, E.N.13779:2007. "Ventilation for nonresidential buildings-performance requirements for ventilation and room-conditioning systems. Brussels, Belgium.” (2007)

24. G. R. Ruiz and C. F. Bandera, "Validation of calibrated energy models: Common errors." Energies. (2017) 